This is the version of the chapter accepted for publication in Reiher, Cornelia and Kottmann, Nora, (eds.), Studying Japan: Research Designs, Fieldwork and Methods. Baden Baden: Nomos Verlag, pp. 450-454.

https://doi.org/10.5771/9783845292878-450

Accepted version downloaded from SOAS Research Online: http://eprints.soas.ac.uk/31193

Re-use is subject to the publisher's terms and conditions

\title{
Writing for Publication: Eight Helpful Hints
}

\section{Christopher Gerteis}

The University of Tokyo \& SOAS University of London

Research writing is central to the career of all scholars. While there are an increasingly diverse formats in which to present your research, all rely on your ability to present your thoughts in writing. Indeed, good writing is central to the practice of research, and while styles of presentation differ good research writing practices will be central to your success as a scholar.

This essay will lay-out some basic advice I ask less experienced authors to consider as they prepare their research for publication. I serve as editor for both an academic journal and a research monograph (book) series. Most manuscripts that cross my desktop conform to disciplinary conventions in terms of style, content and methodology. However, I occasionally run across a piece of scholarly writing that transgresses good research practice. Such instances are rare, and usually rectifiable so long as the intervention is early enough during the review process. Occasionally, however, I am surprised by an author who declines to revise their manuscript despite the advice of their colleagues, peer-reviewers and editors.

1. The quality of your writing counts. Be sure that your writing is clear and helps the reader come to that conclusion. The number of poorly edited manuscripts that come across my desk is stunning. While I have myself made the mistake of submitting a poorly edited manuscript or two, allow me to advise you to avoid that mistake. Edit, edit again, then edit one more time. And if you are still not sure, engage the services of a professional copy writer. It is very much worth the investment. The right copy editor brings fresh eyes to your project and can see where you are not being clear. Your publisher is not going to do that work for you. The burden is on you to make it read well and align with convention.

2. Whatever your discipline, absolutely make certain you are compliant with established research ethics and have overtly identified any potential conflicts of interest. Social scientists and scientists most commonly work within an awareness of the interrelated issues of ethics and conflicts of interest. Yet, in an increasingly privatized university research environment all scholars, humanities especially, need to clearly identify potential conflicts of interest that can arise from sources of funding and family connections. Failure to do so greatly undermines your credibility as a scholar and causes serious harm to the profession broadly.

3. Accurate source attribution is key. One of my earliest influences as a scholar gave me the best advice I have yet heard: "always cite the source you used, not the source that you wanted to use." At its core, his advice identified one of the greatest temptations for any writer: the desire to look smarter than you are. This can lead to serious breaches of research ethics, which is why established writing-up practices help keep all of us honest. Showing the shoulders your work stands on establishes your credibility. Each author cited serves as a pneumonic that helps your reader understand where your argument fits into the scholarship they have already read. It also helps you explain your thought process in a logical and coherent fashion by using secondary 
literature as sign posts to make it easier for the reader to follow the development of your argument. Showing a logical linkage between what has come before, and where you are going, also lays the foundation of credibility upon which you build the totality of your write-up.

4. Your job as a writer is to persuade the reader to your point of view. Ours is an evidence-driven profession but presenting evidence of the human condition in written form is a Sisyphean challenge. My doctoral thesis supervisor spilt a great deal of red ink on my draft manuscript, and one recurring phrase was "Show me, don't tell me." A simple laundry list of assertations will fall flat, and a simple narrative description of events will make no significant contribution to the field. Scholarship is empirical. Make sure the evidence lines-up with and leads to the conclusion you intended. Your primary job is to show the reader with evidence, well signposted to show the reader how you arrived at your conclusions. A good scholar must write in a style with which the reader is familiar and trusts.

5. Keep your notes well organized by using a consistent and easy to access filing system. I often advise my students to use the software tools Evernote and Zotero to help keep their work organized, but there are a number of equally robust software packages that are just as good. The key thing is to have a set of digital tools that allow you to organize your on-going research notes and evolving bibliography. In a book length research project, your dataset is going to become unwieldy very quickly. So, make sure you start your project with a clear organizational system in place, and be certain to make regular back-ups to a cloud storage account or an external hard drive. You do not want to lose your research to a system crash; it happens more often than you want to know.

6. Do not exaggerate a gap in the scholarly literature. As a journal editor I have mentored many first-time authors who felt obliged to carve their niche in the field by overstating their case. A minor gap can still be significant enough to warrant an article - indeed article length projects often do examine the smaller problems within the human condition. While your colleagues do not want to meditate on minutiae, it is nonetheless important for us to know when something small is important. Show us how that is the case, but do not feel like you have to make it bigger than it is.

7. Criticize, critique, or revise, but do not attack. It can be remarkably attractive to want to use your manuscript as a vehicle to attack a scholar or public figure. Discretion is often the better part of valor, especially for an early-career scholar, so keep your discourse civil. You may even find that your thinking changes over time and it will be easier to look back at your work.

8. One final piece of advice: write with passion. Try to write subjects in which you are interested and feel strongly about. Passion can inform writing and help to keep the reader's attention. While you want to avoid flowery language - adjectives and adverbs especially - precise imagery and vivid narrative can engage and hold a reader long enough to hear you out. You don't want to manipulate the reader, but you do want their attention. And skillful, passionate prose can help you do that. 
In: Cornelia Reiher and Nora Kottmann (eds.) Studying Japan: Research Designs, Fieldwork and Methods (Baden Baden: Nomos Verlag, forthcoming in 2020).

The advice I have laid-out in this essay will help you establish a good basic framework for thinking about writing, and leaves room for you to develop your own approach to research writing along the way. Your career is yours, and your personal style - your approach - should be distinctive and unique. Following established writing practices is going to be central to your career, and establishing good practices early on will make it all the easier to succeed, but it is just as important that you blaze new paths and explore new intellectual territory. Be yourself. You are your own best asset. 